\title{
Study of Droplets Size Distribution and Spray Performance of Combined Trapezoid Spray Tray (CTST)
}

\author{
Liang $\mathrm{He}^{1, \mathrm{a}}$, Chunli $\mathrm{Li}^{1, \mathrm{~b}}$ and Hai Shan ${ }^{1, \mathrm{c}}$ \\ ${ }^{1}$ School of Chemical Engineering and Technology, Hebei University of Technology, Tianjin \\ 300130, \\ China \\ a heliang6020@126.com, ${ }^{\text {b }}$ ctstlcl@hebut.edu.cn, ${ }^{\text {c }}$ shanhai_xgkj@163.com
}

\begin{abstract}
Keywords: CTST; droplet size distribution; spray angle; gas velocity
Abstract: Liquid droplet size distribution and spray has the direct influence upon the combined trapezoid spray tray (CTST). This paper makes use of experimental tower with the diameter of 570mm and high speed camera to conduct the research on the liquid droplet size distribution and spray of the high speed camera. The results show that: Under the spray operation, liquid droplet size distribution is more suitable for upper limit logarithmic normal distribution function; Under the different clear liquid heights, liquid droplet size changes along with the change of gas velocity; In the case of fixed clear liquid height, liquid droplet size $D_{32}$ will decrease along with the increase of kinetic energy factor in plate hole; In the case of same kinetic energy factor in plate hole, liquid droplet size D32 will decrease along with the increase of clear liquid height; Gas velocity of spray hole is the main factor influencing the spray angle; Along with the increase of gas velocity and liquid flow, spray angle will increase and range is smaller; With the increase of gas velocity, the influence of increase of liquid flow upon the spray angle will gradually be weakened; With the increase of gas velocity and liquid flow, liquid droplet distribution within the spray angle tends to be more uniform, but the increase of gas velocity makes the increase area of distribution density mainly concentrates on between $\left[5^{\circ}, 20^{\circ}\right]$ and $\left[40^{\circ}, 50^{\circ}\right]$. Liquid film speed distribution on the spray hole has the tendency of upper big and lower small. Liquid film speed increases with the increase of gas velocity, and presents the slight decrease with the increase of liquid flow.
\end{abstract}

\section{Introduction}

Tower equipment occupies a very important position in the industrial production and is widely applied to the biological pharmaceutical, oil refining, chemical industry and other fields. Trays are the important components of the tray column, the performance of which concerns directly the production plant's investment, energy consumption and the cost. People have been focusing on the research on tray with new type, and a series of new type tray with reasonable structure, good performance, convenient industrial production application also are launched at home and abroad. There are SP-tray ${ }^{[1]}$ under the research of University of Alberta, shell's ConSep tray ${ }^{[2]}$ under the research and development of Royal Dutch Shell, ECMD tray and MD tray ${ }^{[3-4]}$ of UOP, BiFrac tray, Superfrac tray and Nye tray ${ }^{[5]}$ launched by Koch-Glitsch, Triton tray ${ }^{[6]}$ launched by Norton abroad. There are directed float valve tray ${ }^{[7-8]}$ developed by East China University of Science and Technology, compound tray technology ${ }^{[9-10]}$ and DJ tray developed by Zhejiang University, ADV tray ${ }^{[11]}$ developed by Zehua, CTST series ${ }^{[12]}$ developed by Hebei University of Technology etc.

This paper conducts the study on the CTST newly developed by Hebei University of Technology. CTST has been successfully applied to the industry, and the practice proves that it has good technical and economic indexes. Compared with other trays at home and abroad, tray efficiency, pressure drop and operating flexibility of CTST are at a better level, and is the only tray with superficial kinetic energy factor breaking through 3.0. With the unique space structure and gas-liquid flow characteristics, CTST has the excellent anti-clogging resistance and defoaming performance and reached the result of Energy-saving on a wide-range degree in the chemical Energy-saving technology field. 
Table 1 below lists the comparison of CTST and the new type tray and its performance parameters developed at home and abroad in recent years:

Table 1 Comparison of Performance Parameters of Various New Type Trays at Home and Abroad

\begin{tabular}{|c|c|c|c|c|c|}
\hline \multirow[b]{2}{*}{ Name of tray } & \multirow[b]{2}{*}{$\begin{array}{l}\text { Development } \\
\text { unit }\end{array}$} & \multicolumn{4}{|c|}{ Tray performance } \\
\hline & & $\begin{array}{l}\text { Upper limit of } \\
\text { superficial kinetic } \\
\text { energy factor / } \\
{\left[\mathrm{kg}^{1 / 2 /}\left(\mathrm{s} \mathrm{m}^{1 / 2}\right)\right]}\end{array}$ & $\begin{array}{l}\text { Tray pressure } \\
\text { drop is lower } \\
\text { than F1 float } \\
\text { valve }\end{array}$ & $\begin{array}{l}\text { Operatio } \\
\mathrm{n} \\
\text { flexibility }\end{array}$ & $\begin{array}{l}\text { Tray efficiency } \\
\text { is higher than } \\
\text { F1 float valve }\end{array}$ \\
\hline ADV float valve & $\begin{array}{l}\text { Tsinghua } \\
\text { University }\end{array}$ & $2.0-2.5$ & $10 \%$ & $3.5-5.0$ & $10-20 \%$ \\
\hline Directed float valve & $\begin{array}{lr}\text { East China } \\
\text { University } \text { of } \\
\text { Science and } \\
\text { Technology }\end{array}$ & $1.8-2.0$ & $10-30 \%$ & $4.0-5.0$ & $10-15 \%$ \\
\hline $\begin{array}{l}\text { Trapezoidal float } \\
\text { valve }\end{array}$ & $\begin{array}{l}\text { Luoyang } \\
\text { Petrochemical } \\
\text { Engineering } \\
\text { Corporation }\end{array}$ & $1.5-2.0$ & $10-30 \%$ & $4.0-4.5$ & $5-10 \%$ \\
\hline HAVTH & $\begin{array}{l}\text { Tsinghua } \\
\text { University }\end{array}$ & $1.5-2.0$ & $30-40 \%$ & $3.5-5.5$ & $10-20 \%$ \\
\hline Directed sieve tray & $\begin{array}{l}\text { Beijing } \\
\text { University of } \\
\text { Chemical } \\
\text { Technology }\end{array}$ & $2.0-2.5$ & $10-30 \%$ & $3.0-4.0$ & $5-10 \%$ \\
\hline DJ tray & $\begin{array}{l}\text { Zhejiang } \\
\text { University of } \\
\text { Technology }\end{array}$ & $2.0-2.5$ & $10-15 \%$ & $3.5-4.0$ & $5-10 \%$ \\
\hline SuperF-RAC & Koch-Glitch & $2.0-2.5$ & $5-10 \%$ & $3.5-4.5$ & $5-30 \%$ \\
\hline Nye & Koch-Glitch & $2.0-2.5$ & $10-15 \%$ & $4.0-4.5$ & $5-10 \%$ \\
\hline Screen & Koch-Glitch & $2.0-2.5$ & $5-15 \%$ & $3.5-4.5$ & $5-10 \%$ \\
\hline NewVST & Mitsui & $2.0-2.5$ & $10-30 \%$ & $4.0-5.0$ & $10-20 \%$ \\
\hline CTST & $\begin{array}{l}\text { Hebei University } \\
\text { of Technology }\end{array}$ & $3.0-3.4$ & $10-30 \%$ & $4.0-6.0$ & $10-40 \%$ \\
\hline
\end{tabular}

Liquid droplet size distribution condition and its size will directly influence the hydrodynamics characteristic and mass transfer performance of the tray, the research on liquid droplet size distribution is very important to the improvement of the tray. The research of previous researcher on the liquid droplet size distribution and spray performance of CTST is not enough, therefore, this paper conducts the research on the liquid droplet size distribution on this basis, and conducts the detailed research on the gas velocity of spray hole, liquid flow, spray angle and liquid droplet distribution density and other spray performance for providing basis for the further improvement and optimization of CTST.

\section{Experimental Method}

The experimental device is as follows: The system is air-water system, and the tower is the organic glass tower with diameter of $570 \mathrm{~mm}$ and tray spacing of $350 \mathrm{~mm}$. High speed camera is used to take photos of instant state of CTST spray for obtaining the instantaneous information of liquid film and liquid droplet, and image processing technique is used to conduct the monitoring of the location of liquid droplet and data related to the movement. The operating conditions are shown in Figure 1. Main equipment includes air blower and pump, measuring equipment includes micro differential pressure meter, high speed camera and acquisition equipment etc. 


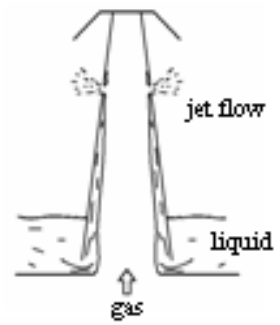

Figure 1 Schematic Diagram of operation status

Experimental process and device are as shown in Figure 2:

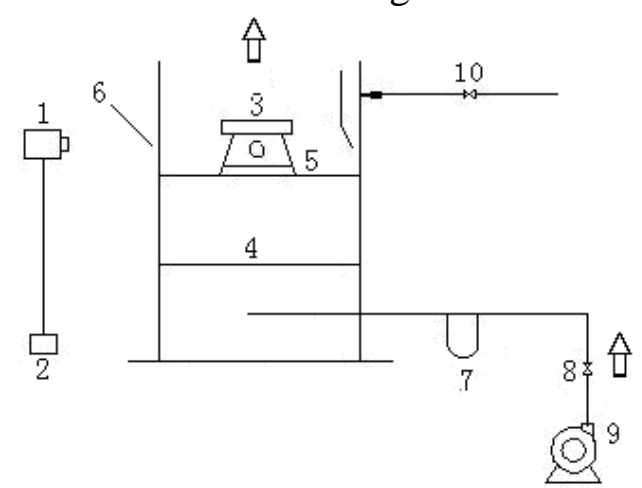

1. High-speed camera 2. Data acquisition devices 3. CTST cap 4. Gas distribution plate 5. Experimental tray 6. Experimental column 7. Micromanometer 8. Adjusting wing valve 9. Air blower 10. Water pipe

Figure 2 Schematic Diagram of Experimental Process

Experimental process is: Gas is pushed through the air blower, with flow controlled by the butterfly valve into the experimental tray, flow of gas entering the tray shall be measured by pitot tube. Gas enters into the cover body from down to top through the distribution plate and plate hole, and then sprays out from the spray hole and top channel. Experimental liquid is directly added to the rectangular groove above tray through the water pipe, the majority of liquid falls back to the plate after the ascension and spray, the minority of liquid splashes out due to the winding of raising gas. Quantity of liquid splashing out is supplemented with the quantity of water intake. When the clear liquid layer is stable, liquid volume added will keep stable. Liquid droplet size and nozzle parameters are measured by high speed camera.

\section{Experimental Result and Discussion}

Mathematical Description For Liquid Droplet Size Distribution. We usually conduct the research on the particle size distribution with the average diameter of the particle. It is against a group of particle swarm, and its main meaning is assuming that the uniform particle swarm with the same size is used to replace the non-uniform particle swarm with different actual size. This paper conducts the research on the liquid droplet size distribution in the flow field of CTST with characteristic value of $D_{32}$. Its definition is using the uniform particle swarm with diameter of $D_{32}$ to replace the non-uniform particle swarm with different sizes, making the ratio of total volume and total surface area under such two situations keep unchanged. Therefore, assuming that the total volume of actual particle swarm is $V_{p}, S_{p}$ represents total surface area, $D_{u}$ represents the diameter of uniform particle, $D_{\max }$ represents the diameter of the maximum particle in the particle group, and $N$ represents the total number of particle swarm. Then:

$$
\begin{gathered}
V_{p}=\frac{\pi}{6} \int_{0}^{D_{\max }} D^{3} d N \\
S_{p}=\pi \int_{0}^{D_{\text {max }}} D^{2} d N
\end{gathered}
$$

The following formula can be obtained according to the definition: 


$$
\frac{V_{p}}{S_{p}}=\frac{\frac{\pi}{6} \int_{0}^{D_{\max }} D^{3} d N}{\pi \int_{0}^{D_{\max }} D^{2} d N}
$$

Assuming that total volume of the uniform particle group is $V$, total surface area is $S$, and total number of particle group is still $N$, then:

$$
\begin{aligned}
& V_{p}=N \cdot \frac{\pi}{6}\left(D_{30}\right)^{3} \\
& S_{p}=N \cdot \pi\left(D_{32}\right)^{2}
\end{aligned}
$$

Therefore,

$$
\frac{V}{S}=\frac{1}{6}\left(D_{32}\right)
$$

According to the definition $\frac{V}{S}=\frac{V_{p}}{S_{p}}$,

$$
\frac{\frac{\pi}{6} \int_{0}^{D_{\max }} D^{3} d N}{\pi \int_{0}^{D_{\max }} D^{2} d N}=\frac{1}{6}\left(D_{32}\right)
$$

The general formula of $D_{32}$ can be further obtained according to the above formula:

$$
D_{32}=\frac{\int_{0}^{D_{\max }} D^{3} d N}{\int_{0}^{D_{\max }} D^{2} d N}=\frac{\sum N_{i} D_{i}^{3}}{\sum N_{i} D_{i}^{2}}
$$

Liquid Droplet Size Distribution Result. The following, as shown in Figure 3 6, is the liquid droplet size distribution result:

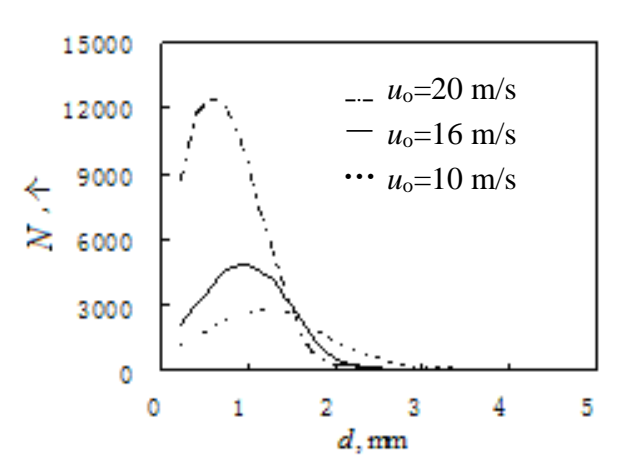

Fig.3 Droplet size distribution at different $u_{o}$

$$
\left(\alpha=8^{\circ}, h=50 \mathrm{~mm}\right)
$$

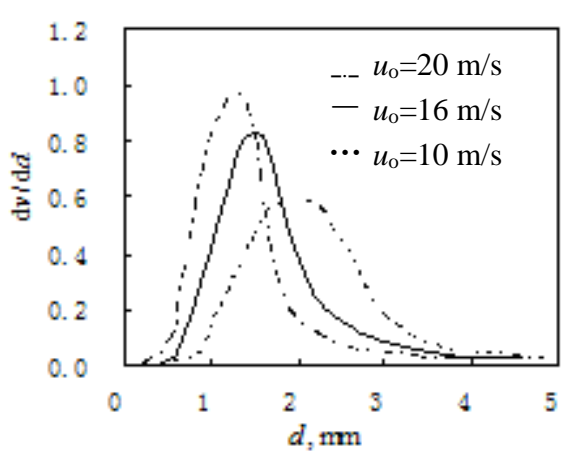

Fig.4 Droplet size distribution on volume fraction at different $u_{o}$

$$
\left(\alpha=8^{\circ}, h=50 \mathrm{~mm}\right)
$$

From figure 3 4, the liquid droplet with diameter of less than $2 \mathrm{~mm}$ occupies the majority under various experimental operation conditions. The influence of gas phase speed upon the liquid droplet size distribution is more obvious, and the increase of gas velocity makes the larger proportion of small liquid droplet, which shows the higher dispersion degree of the liquid. When the gas velocity is same and liquid height is different, the dispersion degree of the liquid droplet has slight reduction but not obviously along with the increase of liquid layer height. 


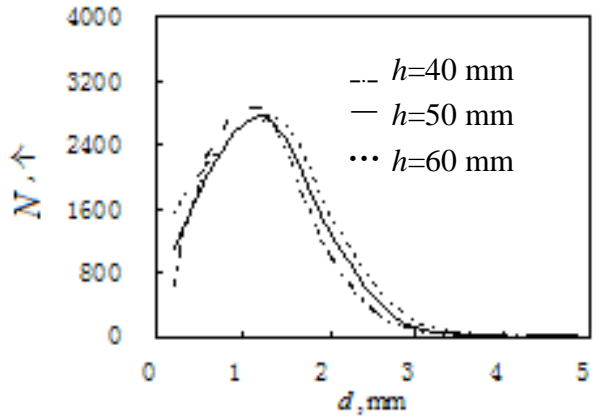

Fig.5 Droplet size distribution at different $h$

$$
\left(\alpha=8^{\circ}, u_{o}=10 \mathrm{~m} / \mathrm{s}\right)
$$

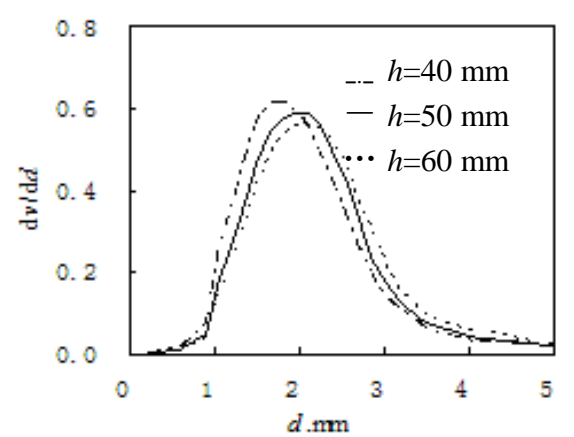

Fig. 6 Droplet size distribution on volume fraction at different $h$ $\left(\alpha=8^{\circ}, u_{o}=10 \mathrm{~m} / \mathrm{s}\right.$ )

Upon the analysis on the above figure 5 6, the force and energy required by the liquid droplet breakdown are from gas. Therefore, with the increase of gas velocity, the gas will produce the bigger shear force upon the liquid, at the same time the gas has more energies to break down the liquid droplet, and liquid elevated quantity will be relatively small under high gas velocity, making the breakdown of the elevated liquid more disperse. When the liquid layer height above tray increases, the liquid elevated quantity also will increase, but the gas velocity and energy have no change, so the dispersion degree of liquid droplet is relatively low. Meanwhile, upon the function distribution test, liquid droplet size distribution is more suitable for the normal distribution function of the upper limit logarithmic.

Influence Of Gas Velocity And Clear Liquid Height Above Tray Upon Liquid Droplet Size Distribution. (1) Influence of plate hole kinetic energy factor $F_{0}$ upon $D_{32}$. Figure 7 is researching the relationship between the $D_{32}$ and plate hole kinetic energy factor $\mathrm{F}_{0}$ under the different clear liquid heights. From the figure, we can see that when the clear liquid height is fixed, the clear liquid height is lower and liquid droplet size decreases faster along with the increase of plate hole kinetic energy factor. This is because with the decrease of clear liquid height, the shear and breakdown of gas raising in high speed is more sufficient, leading to the faster decrease of the final liquid droplet size.

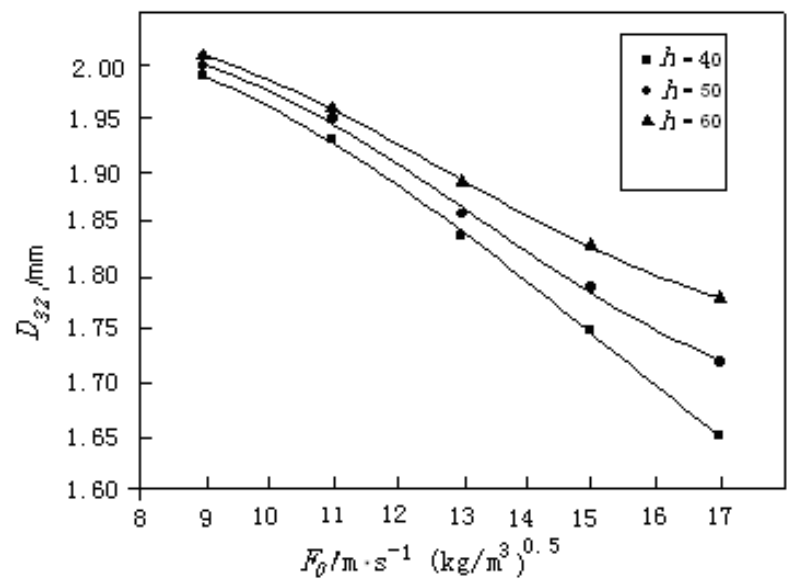

Fig.7Effect of the speed of gas on droplet size

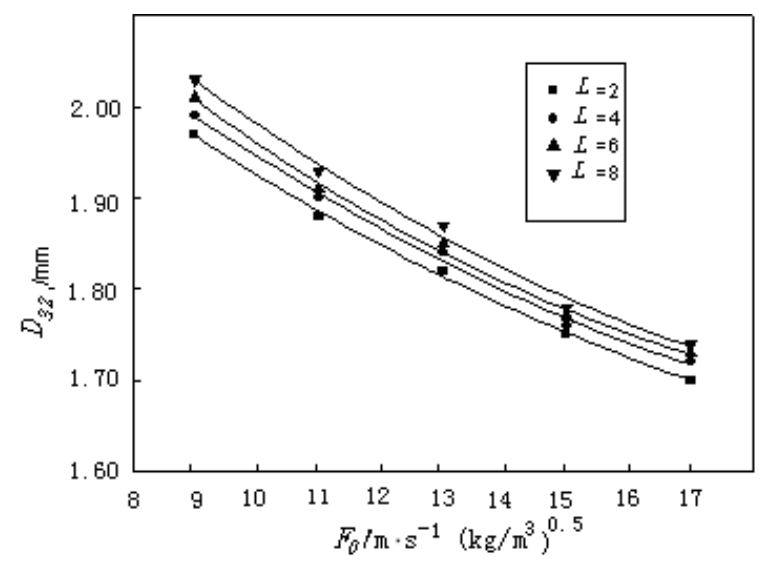

Fig. 8 Effect of the strength of liquid on droplet size

(2) Influence of clear liquid height above tray upon $D_{32}$

For the research on the influence of clear liquid height above tray upon $D_{32}$, this paper adopts the following methods: (1) Keep outlet weir height $h_{w}$ unchanged and only change the liquid flow strength L for further research on the influence of liquid flow strength $L$ upon $D_{32}$; (2) Keep liquid flow strength L unchanged and only change outlet weir height hw for further research on the influence of outlet $h_{w}$ upon $D_{32}$; (3) Finally summarize and discuss the influence of clear liquid height above tray $h$ upon $D_{32}$. 
Figure 8 is the research on the influence of different liquid flow strengths upon liquid droplet size $D_{32}$. From the figure, we can see that when the liquid flow strength is fixed, liquid droplet size $D_{32}$ will decrease along with the increase of plate hole kinetic energy factor. In the case of same kinetic energy factor in plate hole, liquid droplet size $D_{32}$ will decrease along with the increase of liquid flow strength; This is because that the clear liquid height above tray increases along with the increase of liquid flow strength, at the same time, the clear liquid height above tray also will influence the total volume of liquid entering the cover body. With the increase of liquid flow strength above tray, total volume of liquid entering the cover body also will increase, and total volume of liquid elevated will further increase, thus leading to the increase of final liquid droplet size $D_{32}$.

(2)Influence of outlet weir height $h_{w}$ upon $D_{32}$

Figure 9 is the research on the influence of different weir height upon liquid droplet size $D_{32}$. From the figure, we can see that when the weir height is fixed, liquid droplet size $D_{32}$ will decrease along with the increase of plate hole kinetic energy factor. In the case of same kinetic energy factor in plate hole, liquid droplet size $D_{32}$ will decrease along with the increase of weir height; Upon the analysis on reason, the clear liquid height above tray will correspondingly increase along with the increase of weir height, at the same time, clear liquid height above tray also will influence the total volume of liquid entering the cover body; Therefore, with the increase of liquid flow strength above tray, total volume of liquid entering the cover body also will increase, and upon the shear and elevation of high-speed gas elevated, total volume of liquid sprayed out of the spray hole also will increase, thus leading to the increase of final liquid droplet size $D_{32}$.

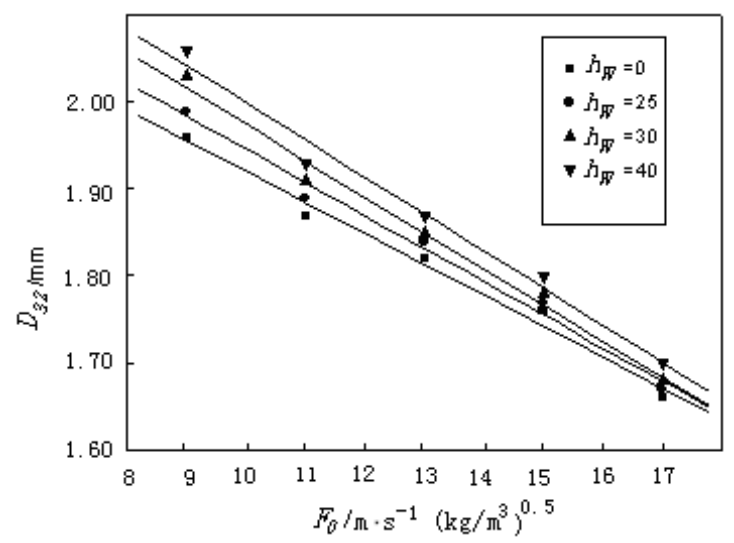

Fig.9 Effect of weir height on droplet size

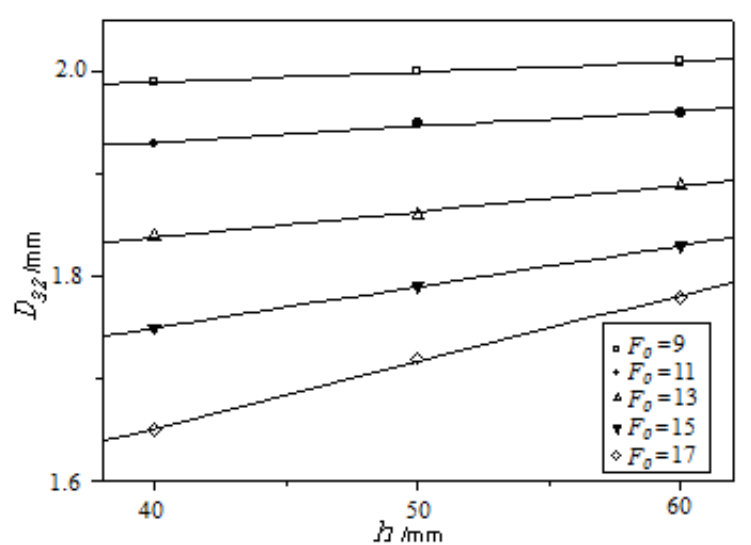

Fig.10 Effect of the clear liquid height on droplet size

(3)Influence of clear liquid height $\mathrm{h}_{\mathrm{L}}$ upon $D_{32}$

Figure 10 is the research on the influence of different clear liquid heights above tray upon liquid droplet size $D_{32}$. From the figure, we can see that when the clear liquid height above tray is fixed, plate hole kinetic energy factor increases, and liquid droplet size $D_{32}$ decreases. In the case of same kinetic energy factor in plate hole, liquid droplet size $D_{32}$ will decrease along with the increase of clear liquid height above tray; For different plate hole kinetic energy factors, the lower the clear liquid height is, the faster the liquid droplet size decreases. This is because: When clear liquid height is low, the shear and breakdown of gas raising in high speed is more sufficient, leading to the faster decrease of the liquid droplet size.

In sum, main factor influencing the liquid droplet size is gas velocity. Therefore, the kinetic energy of gas raising in high speed is the main reason of influencing liquid droplet size distribution. In the case of gas-liquid two-phase normal operation, overflow strength and weir height are the main reason influencing the clear liquid height above tray. With the increase of overflow strength and weir height, clear liquid height above tray also increases, which can be fundamentally explained as: The influence of overflow strength or weir height upon the liquid droplet size is the influence of clear liquid height above tray upon the liquid droplet size. 
Analysis on Influence Factor of Gas Velocity, Liquid Flow, Spray Angle and other Spray Performances of Spray Hole of CTST. According to the curve graph obtained from the experimental result, this paper obtains the change rule of gas velocity, liquid flow, spray angle and liquid droplet distribution density and other spray performances of spray hole of CTST.

Liquid Flow of Spray Hole. The breakdown of CTST upon the continuous liquid is realized after passing through the spray hole. The liquid first is elevated, and then is sprayed out of the cover through the spray hole under the action of gas. As shown in figure 11, elevating amount of CTST will decrease along with the increase of plate hole air energy factor $F_{0}$ and increase along with the increase of clear liquid height above tray $h$. Figure 12 is the change of spray hole liquid flow $Q$ along with plate hole kinetic energy factor $F_{0}$ when clear liquid height above tray is $30 \mathrm{~mm}-50 \mathrm{~mm}$. When plate hole kinetic energy factor is smaller, the absolute elevating amount is large, and liquid flow is larger. With the increase of plate hole kinetic energy factor, the decrease of elevating amount will lead to the decrease of spray hole liquid flow. However, the increase of plate hole kinetic energy factor makes the change of liquid flow become gentle. After the plate hole kinetic energy factor increases to a certain extent, the liquid flow above spray hole also tends to increase. Upon the analysis, with the increase of plate hole kinetic energy factor, though the absolute elevating amount decreases, the decrease degree gradually becomes slow. However, the increase of plate hole kinetic energy factor leads to the increase of gas velocity of spray hole, providing more sufficient power for the external spray of the liquid, and further increasing the spray amount.

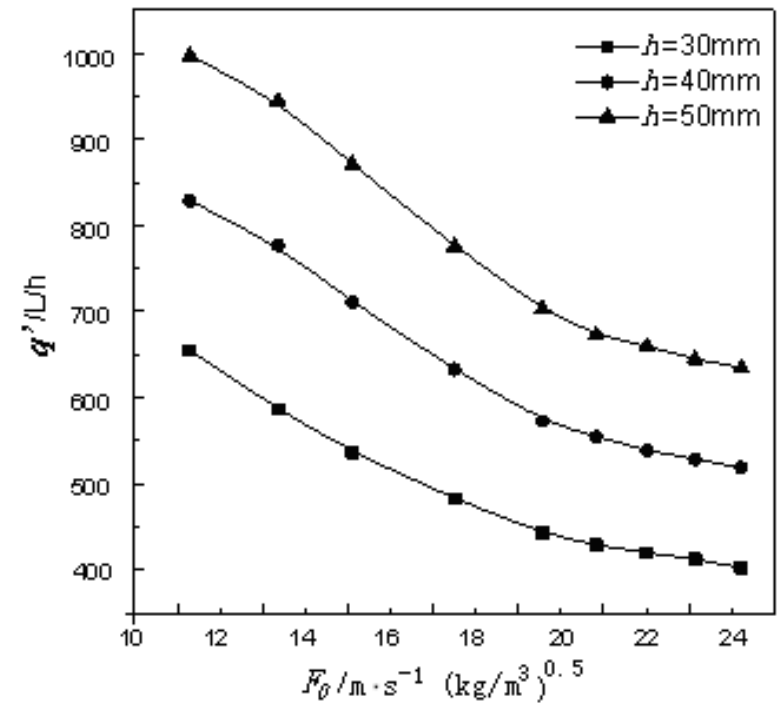

Fig.11 The effect of the plate hole kinetic energy factor on the absolute lifting capacity

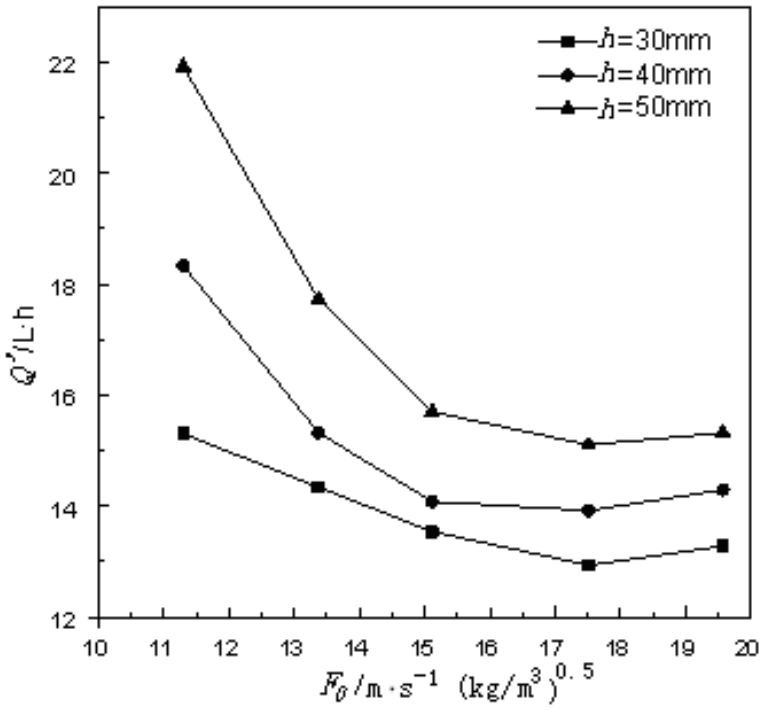

Fig.12 The effect of the plate hole kinetic energy factor on liquid amount of the jet hole

Relationship among the Spray Angle, Spray Hole Gas Velocity and Liquid Flow. Figure 13 is the schematic diagram of spray angle. After the small liquid droplet is formed near the spray hole, as the gas sprayed out moves upwards obliquely away from the cover body, the trajectory is almost the straight line in the early. Within a two-dimensional plane angle with spray hole center as the original point, all liquid droplets keep the upward motion, and this angle is defined as the spray angle of CTST spray hole, recording as $\alpha$ (as shown in Figure 13) The experiment also finds that the motion direction of small liquid droplets formed at the bottom of spray hole is basically parallel with the tray (as shown in Figure 14). Therefore, the lower limit of spray angle is set as the tray parallel surface passing through the lower end of spray hole. 


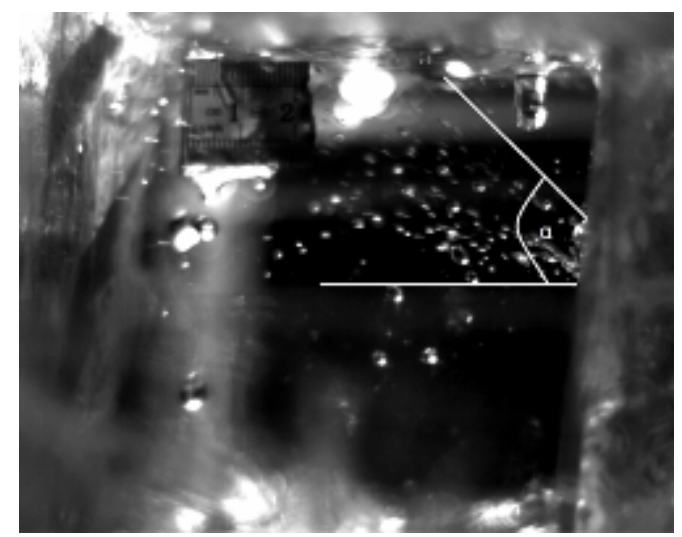

Fig.13 The diagram of spray cone angle

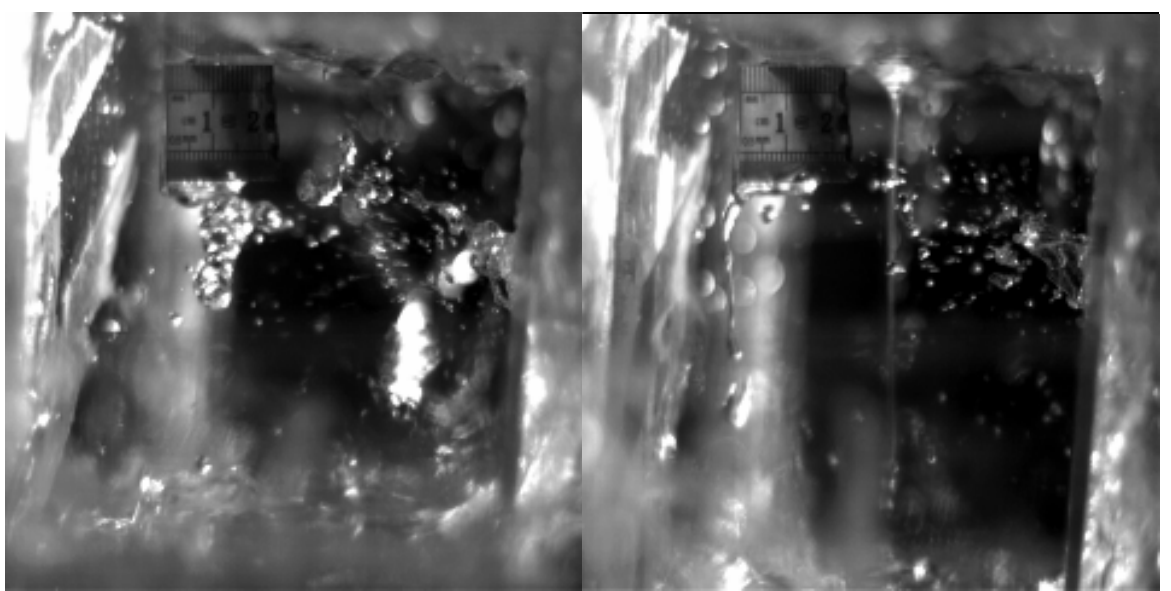

(a) $u_{g}=5.80 \mathrm{~m} / \mathrm{s}, Q=0.013 \mathrm{~m}^{3} / \mathrm{h}$, spray angle; (b) $u_{g}=6.82 \mathrm{~m} / \mathrm{s}, Q=0.013 \mathrm{~m}^{3} / \mathrm{h}$, spray angle
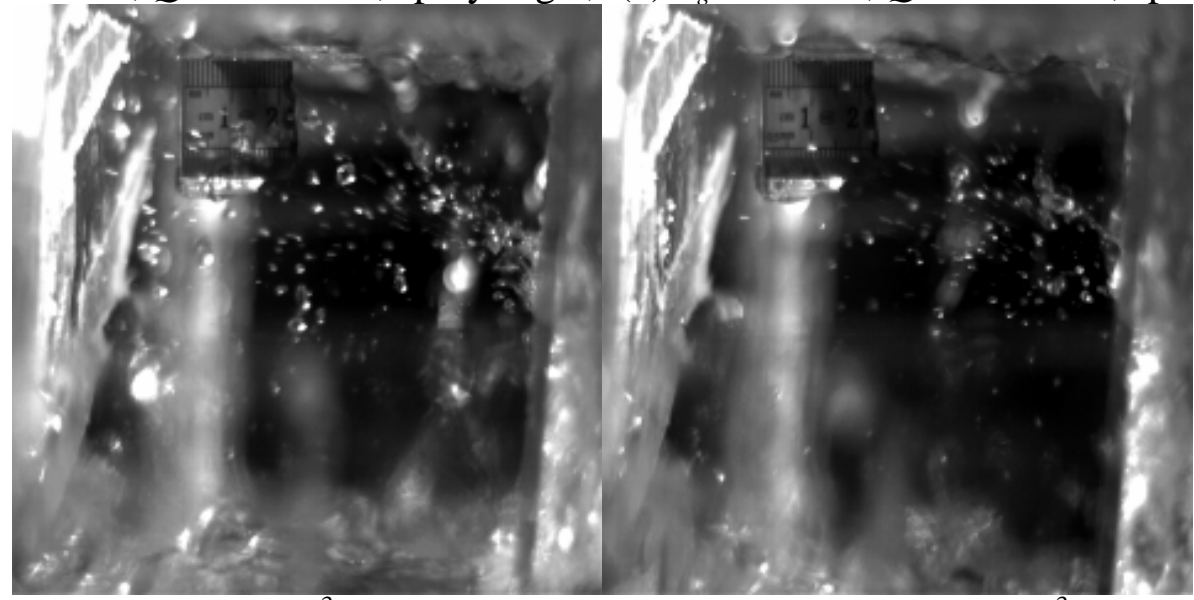

(c) $u_{g}=7.63 \mathrm{~m} / \mathrm{s}, Q=0.013 \mathrm{~m}^{3} / \mathrm{h}$, spray angle; (d) $u_{g}=8.58 \mathrm{~m} / \mathrm{s}, Q=0.013 \mathrm{~m}^{3} / \mathrm{h}$, spray angle

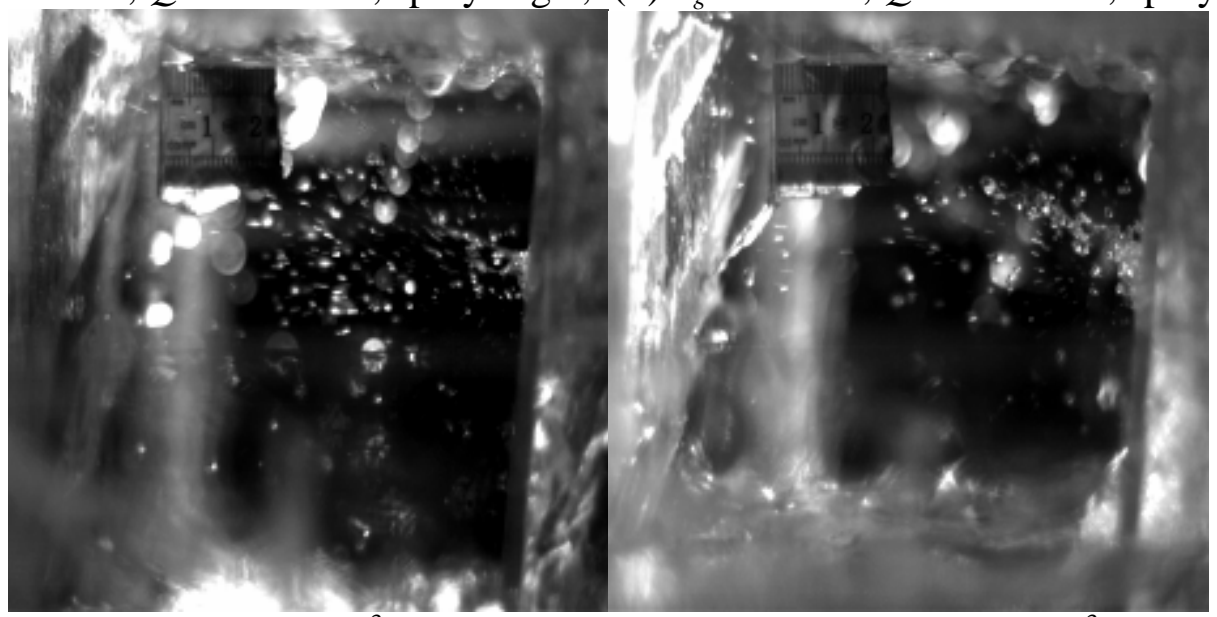

(e) $u_{g}=9.42 \mathrm{~m} / \mathrm{s}, Q=0.013 \mathrm{~m}^{3} / \mathrm{h}$, spray angle; (f) $u_{g}=6.82 \mathrm{~m} / \mathrm{s}, Q=0.014 \mathrm{~m}^{3} / \mathrm{h}$, spray angle 


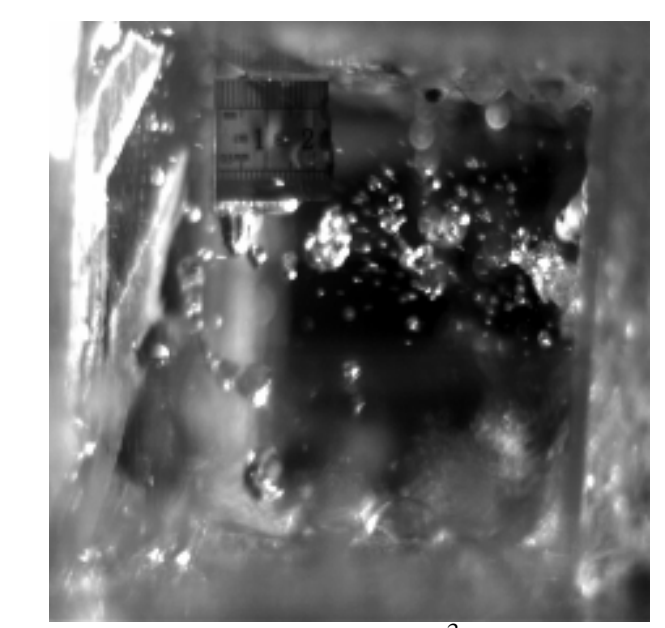

(g) $u_{g}=6.82 \mathrm{~m} / \mathrm{s}, Q=0.015 \mathrm{~m}^{3} / \mathrm{h}$, spray angle

Fig.14 The picture of the spray cone angle under different gas velocity and liquid amount

Figure 15 is the changing curve of the influence of gas velocity of spray hole and liquid flow upon the spray angle $\alpha$. Generally speaking, spray angle arapidly increases with the increase of gas velocity and then becomes stable. For CTST, the change of liquid flow of spray hole is greatly related to the gas velocity of spray hole, so when the gas velocity is lower, the liquid flow increases, and spray angle $\alpha$ also increase obviously; With the increase of gas velocity, the influence of liquid flow upon spray angle $\alpha$ is weakened.

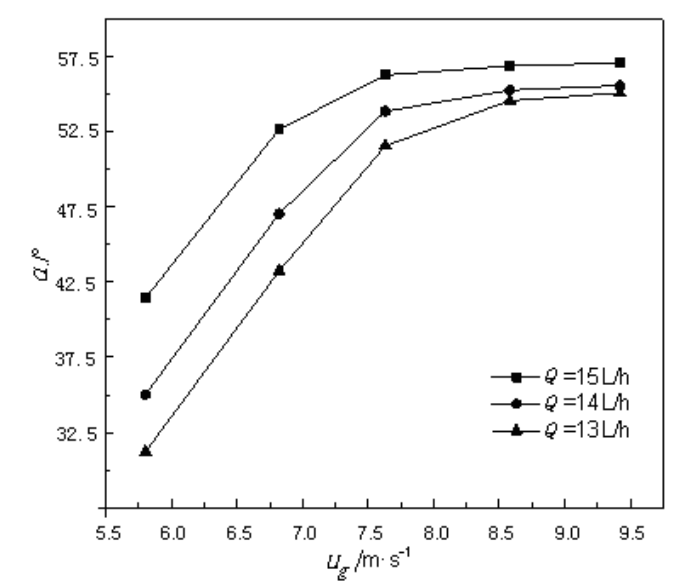

Fig.15 The effect of the spray cone angle under different gas velocity and liquid amount

Distribution Density of Liquid Droplet within Spray Angle. Distribution of liquid droplet within spray angle is not uniform. Distribution density of liquid droplet is used to describe its distribution rule, recording as $P$, namely, proportion of number of liquid droplets in total number of liquid droplets within the scope of certain spray angle $j$. in which, abscissa $j$ represents an angle interval $\left[j-5^{\circ}, j^{\circ}\right]$.

Figure 16 is the curve of distribution density $P$ changing with angle parameter j under different gas velocity of spray hole when liquid flow $Q=15 \mathrm{~L} / \mathrm{h}$. From the figure, we can see that increase of gas velocity makes the distribution density become more uniform with the maximum value in $j=\left[20^{\circ}, 35^{\circ}\right]$. Upon the analysis, aerodynamic force is the main force source of liquid film breakdown. In the case of unchanged liquid flow of spray hole, when gas velocity is lower, part of liquid doesn't break down at the moment of spraying out of the hole due to the non -uniformity of gas velocity distribution on the spray hole, but continues keeping upward motion, and then breaks down fiercely and forms the large amount of liquid droplets under the action of high gas velocity after reaching the middle and upper part of spray hole. After the increase of gas velocity, the aerodynamic force of entire spray hole also increases, making the liquid failing to break down after the film-drawing break down in the elevation process. Meanwhile, the surface with small part of liquid accumulating on the top of spray hole also swells under the larger gas velocity, thus further separation and breakdown for forming liquid droplets. 
Therefore, the increase of gas velocity directly expands the scope of liquid film breakdown, thus making more uniform distribution of liquid droplets.

Figure 17 is the curve about the influence of the change of spray hole flow upon the liquid droplet distribution density in the case of $u_{g}=5.80 \mathrm{~m} / \mathrm{s}$. In the case of fixed gas velocity, with the increase of liquid flow of spray hole, the distribution density scope of liquid droplets is expanded, and distribution within spray angle becomes more uniform; With the increase of liquid flow, the distribution of liquid film makes the increase of liquid film breakdown areas on the spray hole and more extensive distribution location of liquid droplet. Like the influence of gas velocity upon the distribution density, regardless of the change of liquid flow, the maximum value of distribution density always appears within the interval $j=\left[20^{\circ}, 35^{\circ}\right]$. Thus, aerodynamic force within this scope is the strongest. Liquid film breakdown is also the most sufficient under the action of gas.

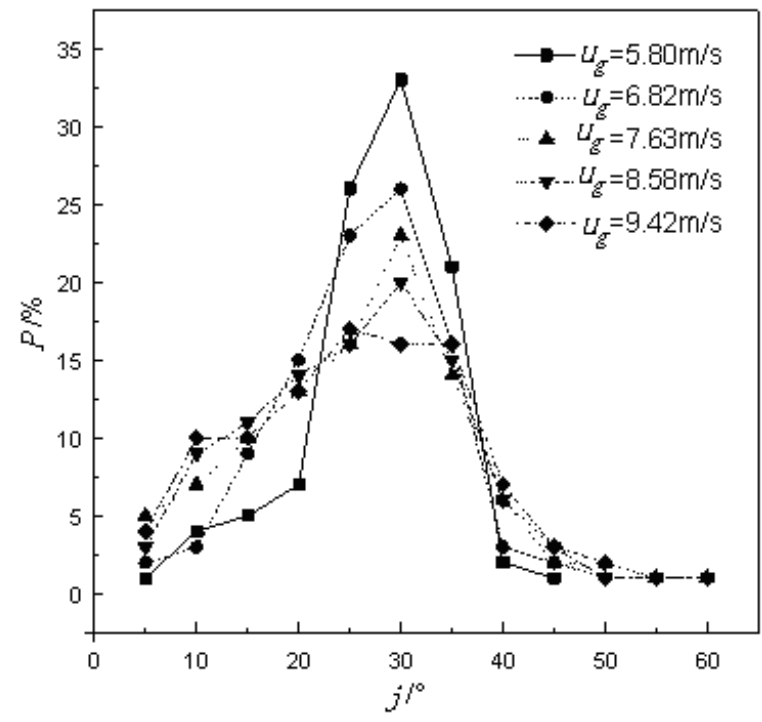

Fig.16 The effect of jet hole gas velocity on the distribution density $(Q=15 \mathrm{~L} / \mathrm{h})$

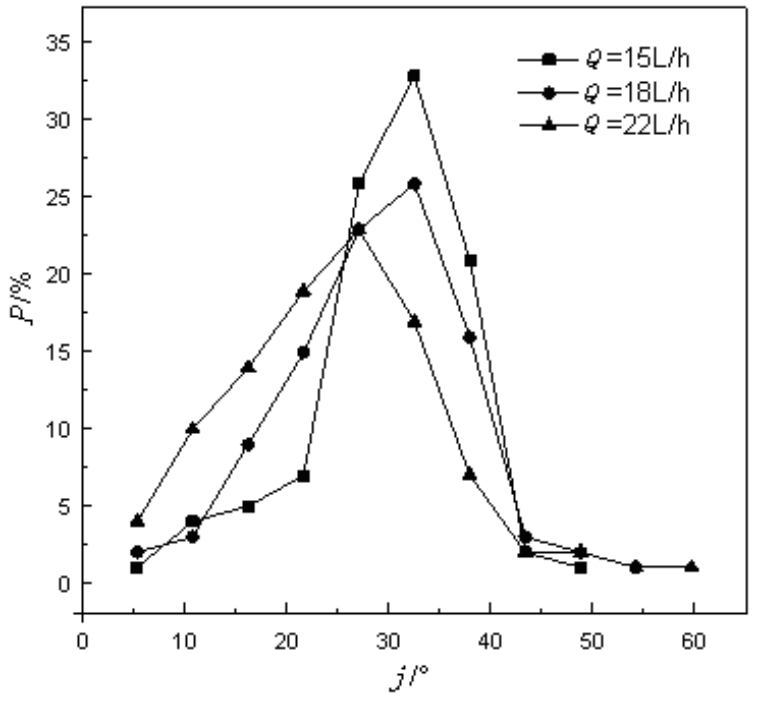

Fig.17 The effect of the liquid amount on the distribution density $\left(u_{g}=5.80 \mathrm{~m} / \mathrm{s}\right)$

Upon the comparison of Figure 16 and Figure 17, we can see that though the increase of gas velocity and liquid flow of spray hole widens the distribution density interval of liquid droplet and makes the distribution more uniform, yet the influence of both upon the distribution density still has the difference. The increase of gas velocity of spray hole promotes the film-drawing of liquid film towards the outside during the elevation, thus greatly increasing the number of liquid droplet formed from the liquid film breakdown at the middle and lower part of spray hole. At the top of spray hole with larger speed, the increase of gas velocity makes the liquid column surface accumulated at the top of spray hole become more unstable, leads to the fierce movement and strips off the liquid, further forming the disperse liquid droplet group. Therefore, the scope of distribution density increasing along with gas velocity mainly is with the scope of $j=\left[5^{\circ}, 20^{\circ}\right]$ and $j=\left[40^{\circ}, 50^{\circ}\right]$. With the increase of liquid flow of spray hole, the difficulty of gas elevating the liquid film becomes bigger. Liquid film distribution becomes uniform, which makes part of liquid film break down into liquid droplet under the action of gas sprayed out in the elevation process. Therefore, distribution density mainly increases within the scope of $j=\left[5^{\circ}, 20^{\circ}\right]$.

\section{Conclusion}

This paper conducts the study on the liquid droplet size distribution and spray performance of CTST with technical and economical indexes being more advanced at home and abroad, and mainly concludes that: 
(1) The study on liquid droplet size obtains the basic rule of liquid droplet distribution of CTST: Under the spray operation, liquid droplet size distribution is more suitable for upper limit logarithmic normal distribution function.

(2) Under the different clear liquid heights, liquid droplet size changes along with the change of gas velocity; In the case of fixed clear liquid height, liquid droplet size $D_{32}$ will decrease along with the increase of kinetic energy factor in plate hole; In the case of same kinetic energy factor in plate hole, liquid droplet size $D_{32}$ will decrease along with the increase of clear liquid height.

(3) Upon the research on the gas velocity of spray hole, liquid flow, spray angle, distribution density of liquid droplet speed, liquid film speed and other spray performances of CTST, it draws the following conclusions:

(1) Gas velocity of spray hole increases along with the increase of plate hole kinetic energy factor.

(2) Along with the increase of gas velocity and liquid flow, spray angle will increase and range is smaller; With the increase of gas velocity, the influence of increase of liquid flow upon the spray angle will gradually be weakened;

(3) With the increase of gas velocity and liquid flow, liquid droplet distribution within the spray angle tends to be more uniform, but the increase of gas velocity makes the increase area of distribution density mainly concentrates on between $\left[5^{\circ}, 20^{\circ}\right]$ and $\left[40^{\circ}, 50^{\circ}\right]$.

\section{Acknowledgement}

This work was supported by the Science and Technology Research and Development Plan of Hebei Province (12276710D).

\section{Symbol description}

$\begin{array}{ll}d & \text { Liquid droplet size, } \mathrm{m} \\ D_{32} & \text { Sauter average diameter, } \mathrm{m} \\ F_{0} & \text { Plate hole kinetic energy factor } \\ h_{W} & \text { Weir height, } \mathrm{m} \\ h & \text { Clear liquid height above tray, } \mathrm{m} \\ L & \text { Liquid flow strength, } \mathrm{m}^{3} /(\mathrm{m} . \mathrm{h}) \\ P & \text { Liquid droplet distribution density, } \% \\ q & \text { Absolute elevating amount, } \mathrm{L} / \mathrm{h} \\ Q & \text { Liquid flow of spray hole, } \mathrm{m}^{3} / \mathrm{h} \\ u_{0} & \text { Gas velocity of plate hole, } \mathrm{m} / \mathrm{s} \\ u_{g} & \text { Gas phase speed, } \mathrm{m} / \mathrm{s} \\ v & \text { Accumulative volume fraction of liquid droplet } \\ \alpha & \text { Spray angle, }{ }^{\circ} \\ \text { Subscripts: } & \\ g & \text { Gas phase } \\ i, j & \text { Direction flow } \\ x, y, z & \text { Coordinate }\end{array}$

\section{References}

[1]Kachur J P, Afacan A, Chuang K T. Chemical Engineering Research and Design, 2004, 82 (7): 813-820

[2]Wilkinson P, Vos E, Konijn G, et al. Chemical Engineering Research and Design, 2007, 85 (1): $130-135$

[3] Sloley A W. Chemical Engineering Progress, 1999, 95 (1): 23-35

[4] Bravo J L. Chemical Engineering Progress, 1997, 93 (7): 36-41

[5] Williams J A. Chemical Engineering Progress, 1998, 94 (3): 23-33

[6] Hauser R. Petroleum Refinery Engineering, 1999, 29 (3): 33-36 
[7]Jiexu Zhang, Zhaopei and Yu'an Li, et al. In Chinese: Chemical Industry and Engineering Progress, 2005, 24 (z1): 64-68

[8]Yongqing Jin, Chunshan Li and Yu'an Li. In Chinese: Guangxi Journal of Light Industry, 2007,1 (1): $51-52$

[9]Lianghua Wang, Jianbing Ji and Kejian Yao, et al. In Chinese: Chemical Engineering(China), 20 00, 28 (1): 14-17

[10]Kejian Yao, Lingren Zhu and Jianbing Ji. In Chinese: Petrochemical Technology, 2000,29(10): $772-776$

[11]Baohua Yang and Yanchun. In Chinese: Petrochemical Design, 2004,21(2): 41-45

[12]Jidong Liu, Chunli Li and Baichun Li, et al. In Chinese: Petrochemical Technology, 2007,36(2): 161-164 